\title{
Chemical Synthesis in Microreactors
}

\author{
Thomas Schwalbe*, Volker Autze, and Gregor Wille
}

\begin{abstract}
Chemical synthesis in microreactors is a novel way of conducting chemistry in a highly controlled way with improved yields at impressive selectivities and with reduced overall effort. This paper describes recent technological progress with the potential as well as the application of the technology to chemical synthesis, discusses novel chemical optimization technology and reports on the transfer of the technology into production.
\end{abstract}

Keywords: Continuous synthesis · Microreactors · Process intensification · Scale-up · Selectivity

\section{Introduction}

The extension of chemical synthesis from laboratory scale to so-called kilo-lab or, even further, to technical processes faces a variety of problems known since organic chemical products were introduced to market at the end of the 19th century. Although remarkable progress was elaborated in the fields of plant security, efficiency and environmental protection, temperature control and efficient mixing in large batch vessels are still major challenges. Since nonhomogenous temperature distribution may result in the formation of undesired sideproducts and investments for cooling systems are enormous, there is still a demand for improved solutions. Some years ago a promising approach was found to replace the reliable but limited batch vessel technology by a flexible and more efficient alternative: microreaction technology (MRT). Fig. 1 shows a general scheme for microreactor (MR) assembly along with a photograph of the reaction chamber (Fig. 1b).

The construction and successful application of the first microreactor demonstrated the capabilities of a modern concept in which classical problems of large scale synthesis are excluded from the beginning. Its major benefits are:

${ }^{*}$ Correspondence: T. Schwalbe

CPC - Cellular Process Chemistry Systems GmbH Frankfurt Site

Hanauer Landstrasse 526/G58

D-60343 Frankfurt am Main, Germany

Tel.: +496941092320

Fax: +496941092322

E-Mail: schwalbe@cpc-net.com

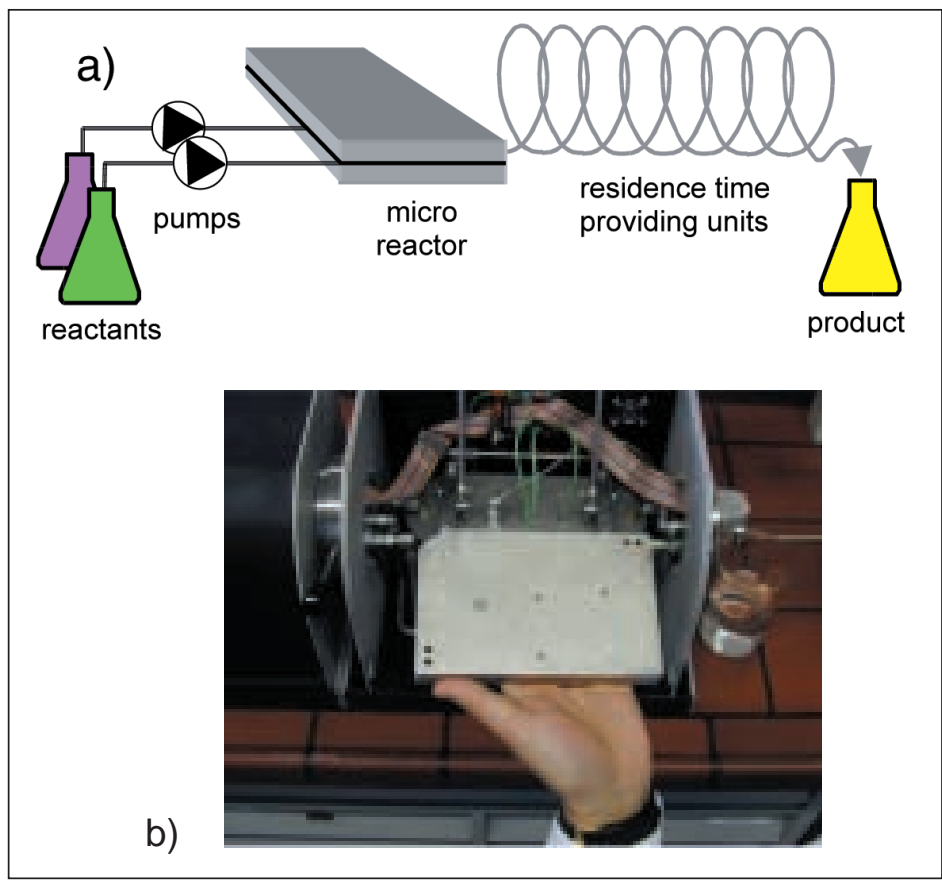

Fig. 1. a) Typically, a MR has a cell dimension of $2 \mathrm{ml}$, a continuous flow rate of $1-10 \mathrm{ml} / \mathrm{min}$, throughput of up to $140 \mathrm{~g} / \mathrm{h}$ and channel dimensions ranging from sixty to several hundred micrometers. b) Photograph of a microreactor.

- An improved surface to volume ratio ensures better temperature control.

- Very efficient mixing inside the reaction cell prevents concentration gradients.

- The small reaction volume in combination with efficient heat absorption provides excellent plant security [1].

- In contrast to classical procedures development activity is not required for a laboratory or kilo-lab synthesis once performed in a microreactor. Enhanced amounts are available easily by combination of several microreactors without changing the reaction parameters inside the individual cells ('numbering-up').

- MRT means continuous process running up to $24 \mathrm{~h}$ per day.

Chemical Synthesis in Microreactors in this paper describes findings and concepts at the cross section from chemistry via synthesis and arriving at chemical synthesis and microreactors in the wider context of micro electric mechanical systems (MEMS), micro total analysis systems $(\mu$-TAS), MRT and microfluidics. In this segment it specifically aims at contributing 
to the pertaining and intentional construction of molecular function in continuous process systems from research to commercial production, in other words the chemistry aspects of the product life cycle of high value added functional molecules. The scientific mainstream of this paper discusses the impact of microreactors on chemical reactions, yields and selectivity. However, the technology has a vast economical impact that fuels investment of all global industrial leaders today. It will change the way we do chemistry in the near future.

\section{Chemical Synthesis in \\ Microreactors}

\subsection{Chemical Targets from an Industrial Perspective}

In reporting the status of the technology it is worthwhile to allocate recent findings in the field to an industrial grid which is biased towards organic molecules and loosely correlates annual chemical output unit with the number of relevant chemical entities. The following trends can be observed: Annual chemical output is closely associated with the average annual output of a production unit, i.e. plant size. This, of course, is true at the prevailing vertical organization of the value added chain that determines the logistics and commercial framework for a chemical's way into the market. The added value is negatively correlated with its annual output. Since natural gas and cracked oil products are primary sources of starting materials for higher value added chemicals and functional chemicals, low viscosity products (gases) are often if not predominantly found at the high output end of chemicals.

In this grid it is worthwhile to distinguish basic chemicals (1), commodities (2), specialties (3), fine chemicals and functional chemicals (4). These segments (Fig. 2) can be further used as denominators for the allocation of microreactor applications. The principle of MRT was demonstrated in the field of 1 [2] and 2 [3]. To the best of our knowledge, no significant applications for MRT were reported in field 3, apart from special reactors for efficient mixing of emulsions [4]. However, synthesis of fine chemicals and functional chemicals (4) are promising fields for the introduction of MRT and will be the main topic in this contribution. A brief summary of the few early MRT applications in field $\mathbf{4}$ is given in Table 1 (for further examples see [5a]). However, recently a wide variety of new syntheses in MR has been examined (Table 2 and references given in section 4.1) and shown to yield improved results over conventional batch processes (Table 4 in section 5).

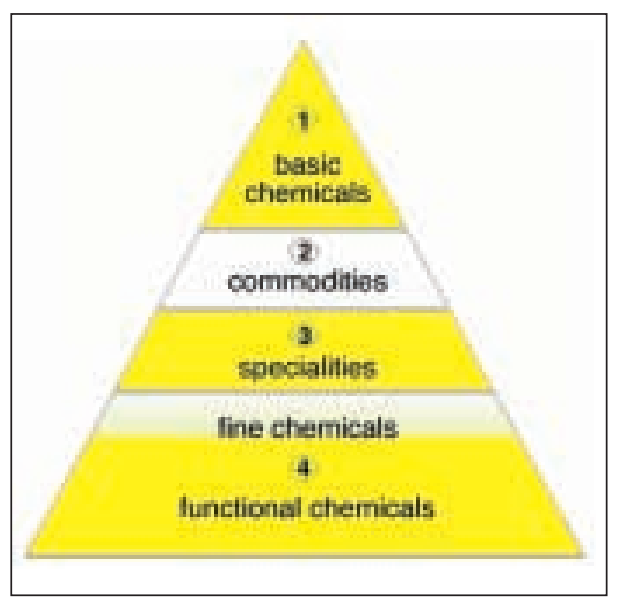

Fig. 2. Distribution of chemical products.

Table 1. Examples the synthesis of fine and functional chemicals (field 4).

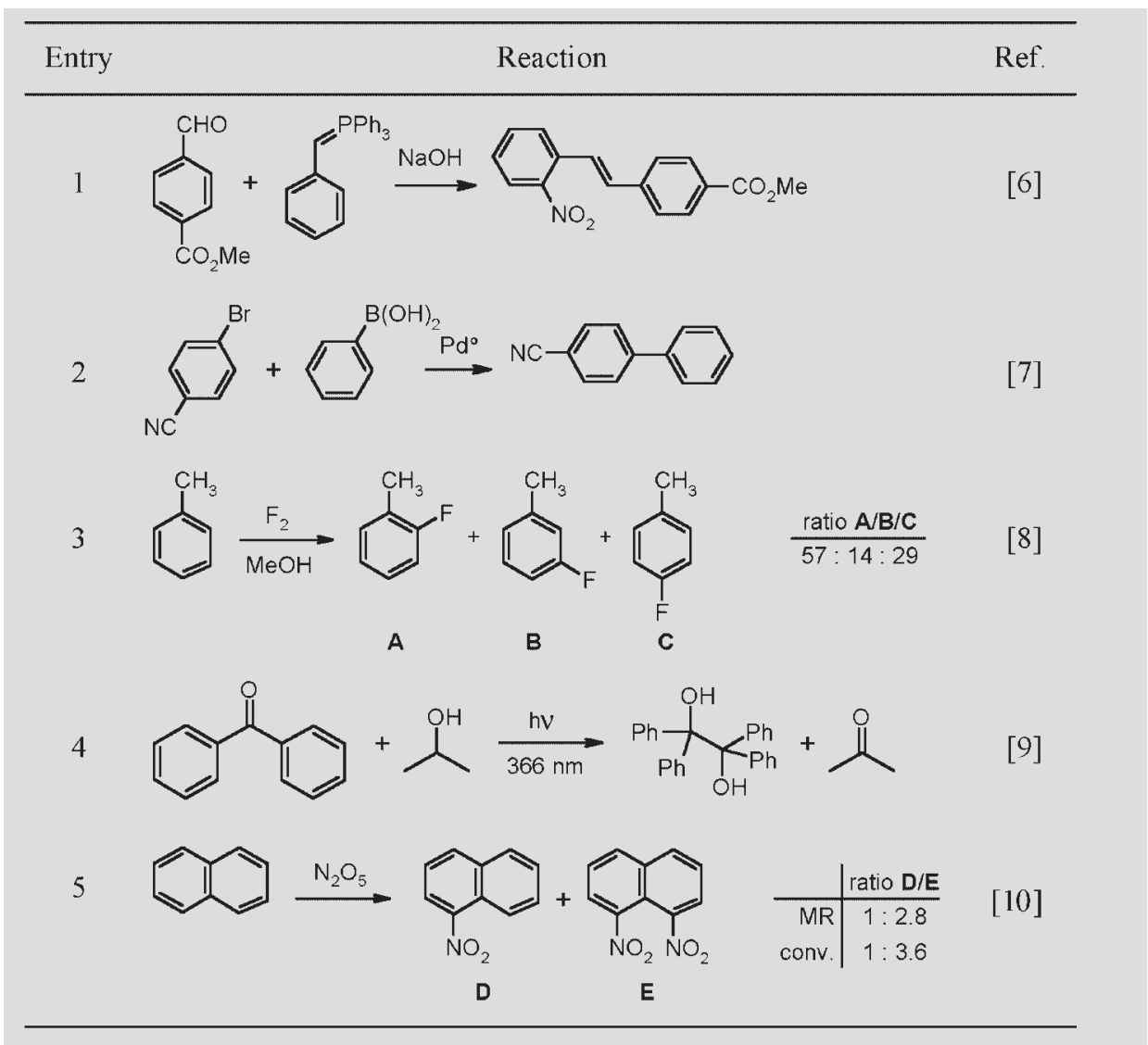

\subsection{Scope and Skill in Chemical Synthesis}

Since we are particularly interested in the synthesis of functional molecules we would briefly like to quote the cornerstones of chemical synthesis as follows. With the Eschenmoser-Woodward synthesis [11] of vitamin $\mathrm{B}_{12}$ the intellectual proof of feasibility for the synthesis of any molecule was completed, Kishi's Palytoxin synthesis [12] suggested the science of synthesis had become a technology, susceptible to rational planning. The market entry of antiviral HIV medication, for example, demonstrated the commercial relevance of complex synthesis [13].
Whilst impressive progress has been made in the field of synthesis we should not fall victim to undue expectations. Though mankind can make any molecule, there are few to plan and execute the synthesis of a given complex target [14]. The more relevant complex structures become in providing functionality industrially the more important it becomes to radically scrutinize non-productive losses of proficient resources. Moreover, once the synthesis of a molecular function is performed, how do we instantaneously ensure a reproducible and resource efficient supply [15]? 


\section{Options to Reduce Complexity and Urgency of Chemical Synthesis}

Putting these objectives into generic terms chemical synthesis simultaneously faces the challenge to become conductible under significantly reduced complexity at increased urgency. Chemical synthesis in microreactors mimics technologies nature developed for the synthesis and rapid procurement of functional molecular response. It also benefits from the alignment of cognitive processes in organizations, an operations research finding.

\subsection{Science and Technology of Cellular Process Chemistry}

\subsubsection{Catalysis and Microcomparti- mental Technology to Orchestrate Quality}

The control over temperature and concentration are crucial elements to secure selectivity in chemical reactions. Both of these parameters are highly dependant on efficient mixing of the reaction components. It is worthwhile for an understanding of microreaction technology to show how it serves in this context.

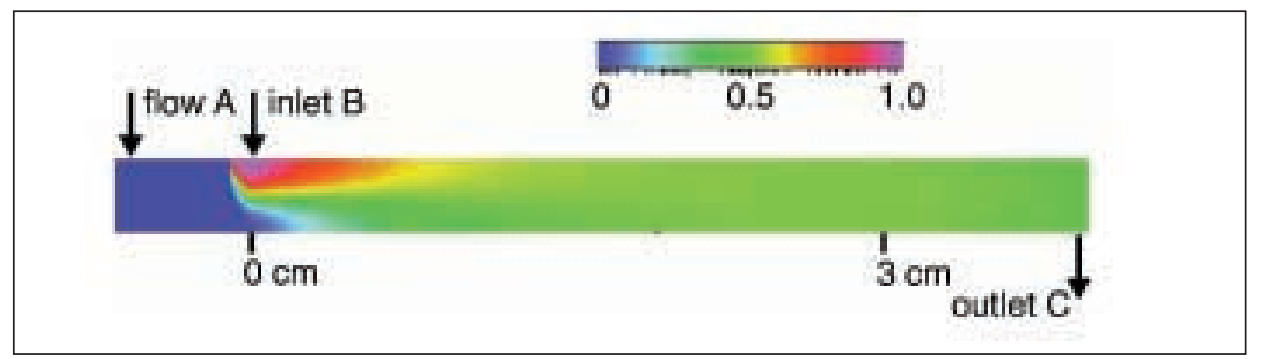

Fig. 3. Concentration distribution in the mixing channel simulating the dimensions of a MR. Compound B is injected (inlet) into a flow of compound A (blue). The green color indicates the 1:1 mixture.

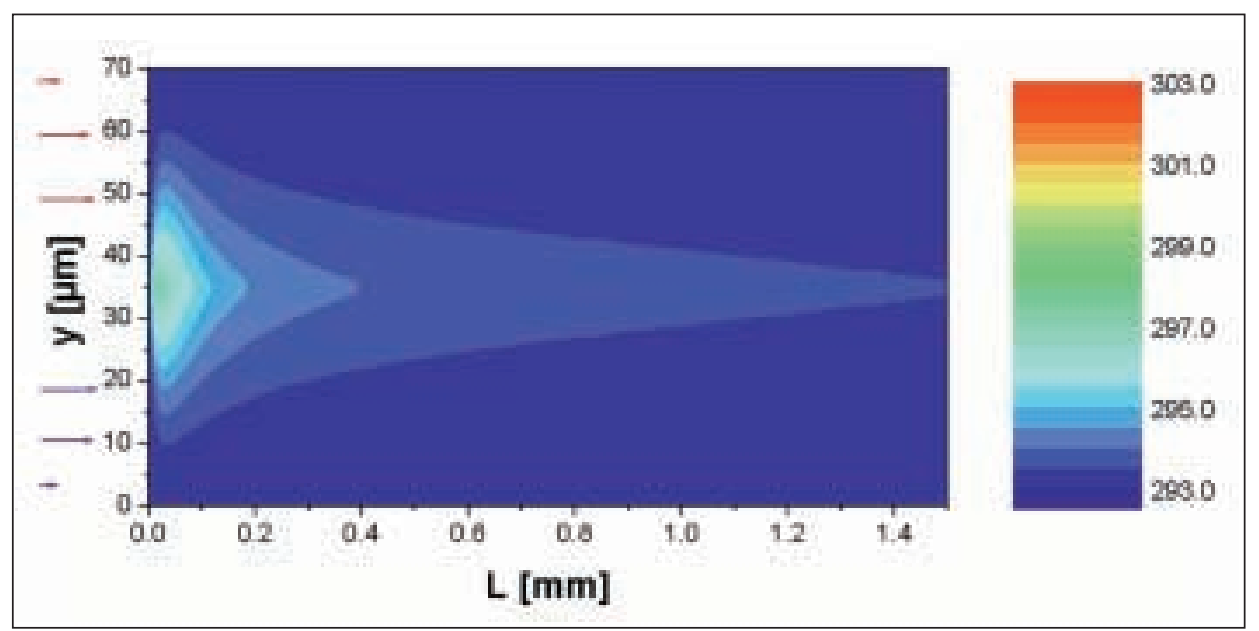

Fig. 4. Temperature distribution in a T-channel simulated for a neutralization reaction of $\mathrm{HCl}$ (red, left) and $\mathrm{NaOH}$ (blue, left). Local temperatures are given according to the color scale (right) in $\mathrm{K}$ ( $y$ is the cell thickness and $L$ the channel length).
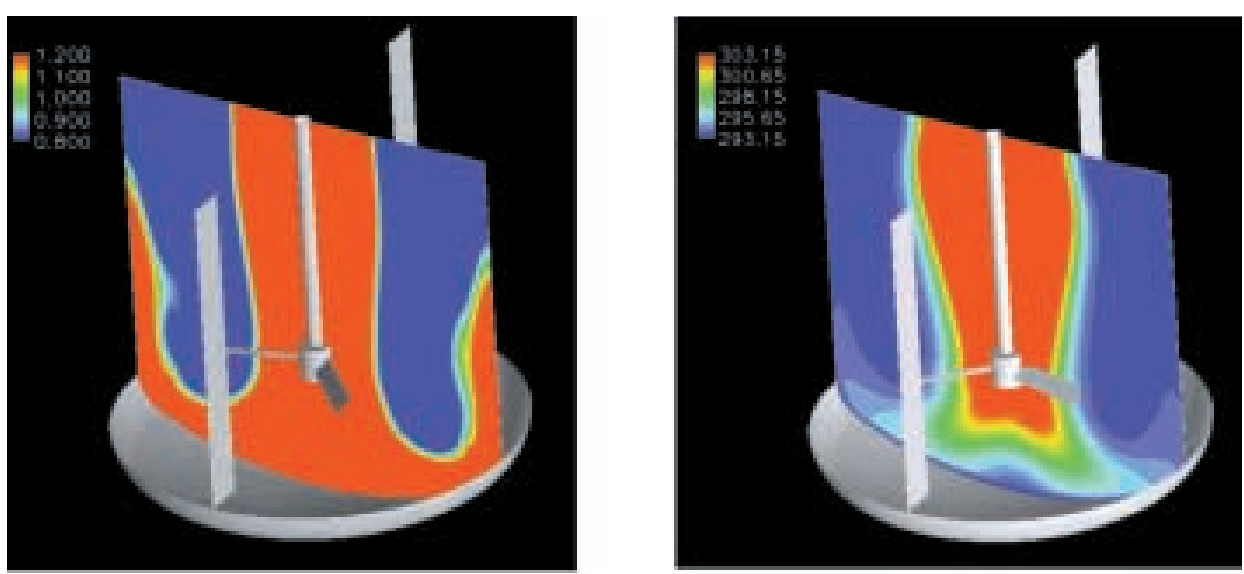

Mixing in microreactors can occur through diffusion between laminar flow layers. According to Fick's first law (Eqn. 1, $\mathrm{J}_{\mathrm{n}}$ being the flow of particles within time, $\mathrm{D}_{\mathrm{o}}$ the diffusion coefficient, $\mathrm{q}$ the cross-section of a tube, $\mathrm{x}$ the distance of displacement by diffusion) the increase of flow $J_{n}$ is a result of small reaction cells as realized in microreactors (channel dimension: less than $100 \mu \mathrm{m})$.

Fick's first law: $\mathrm{J}_{11}=\frac{d n}{q_{0} d t}=-\mathrm{D}_{0} \frac{d n}{d x}$

Thus, conversion in this mixing regime is more reliably controlled by reaction rate for most organic reactions that are slow compared to the diffusion rate. Fig. 3 shows the concentration distribution in a MR and illustrates its efficient mixing properties. Also, the average distances from the reagents flow to the heat exchanging walls of microreactors are small. Heat exchange is driven similarly by a steep temperature gradient (Fig. 4). At every point along the flow channel concentration and temperature gradients are stable. These stable gradients provide better control of reaction conditions compared to conventional synthesis.

For comparison simulations of concentration and temperature distribution in a batch vessel are illustrated in Fig. 5. Compound distribution in this system is less homogeneous than in a MR as a result of inefficient mixing. Further, temperature transfer in a multi- $\mathrm{m}^{3}$ batch vessel is more difficult than in a MR, hence, temperatures fluctuate widely within the vessel. The con-

Fig. 5. Distribution of concentration (left) and temperature in a $5 \mathrm{~m}^{3}$ batch vessel (stirring 500 RPM) simulated for a neutralization reaction $(\mathrm{HCl}$ and $\mathrm{NaOH})$. Levels of temperatures (ranging from $293.15 \mathrm{~K}$, blue, to 303.15 , red) and concentration equivalents (ranging from 0.8 , blue, to 1.2 , red) are given according to the color scale (top left). 
sequences of this lack of control will be discussed below.

In Eyring's equation and the reaction rate equations the influence of a wide temperature and concentration uncertainty respectively can be computed. The energy distribution of molecules at a temperature is described in Eyring's distribution. The Eqns. 2-4 show how a lack of concentration control results in different reaction rates $(r)$ depending on the real concentrations for a unimolecular reaction. In Eqn. 3 and 4 the max. effective concentrations are mentioned according to the simulations for the batch process in Fig. 5. With Fig. 3 it is easily seen that the distribution of reaction rates in a MR is focused since the concentration profile is better controlled.

$$
\begin{aligned}
& \mathrm{r}=\mathrm{k} \times[\mathrm{A}] \\
& \mathrm{r}=\mathrm{k} \times[0.8 \times \mathrm{A}] \\
& \mathrm{r}=\mathrm{k} \times[1.2 \times \mathrm{A}]
\end{aligned}
$$

However, organic chemists are trained to think of transition structures and potential energy profiles along the reaction coordinate (Fig. 6, [16]) to discuss product distribution. On the left side of Fig. 6 a reaction proceeds under kinetic control and the formation of product $\mathrm{C}$ is favored if the activation energy provided to the reaction is limited. These reactions are most favorably run in MR. Excessive energy supply to a reaction allows for the predominant formation of the more stable product through reversible reaction conduct (thermodynamic control, right). Whilst such reactions can in principle be run in MR, there are few cases where we would expect incrementally beneficial results.

In Fig. 7 a normal distribution of particles at certain temperatures is vertically turned and imposed upon the reaction profile (taken from Fig. 6) of competing reactions hence transition structures. Here it is illustrated how increasing temperature quality can be used to increase selectivity under kinetic control of reactions. Alternatively or in combination the increase in temperature control can be used to increase the technical reaction target temperature level and hence increase time/space yield.

Vice versa, selectivity gains or potential increases of reaction temperatures are amplified by simultaneous gains in control of temperature and concentration. High concentration and temperature gradients in microstructure reactors again are drivers of their tight control. Since tighter concentration and temperature control allows a closer tuning of reactions to conversion or selectivity requirements their control works similar to and where combined synergistic with catalysis.

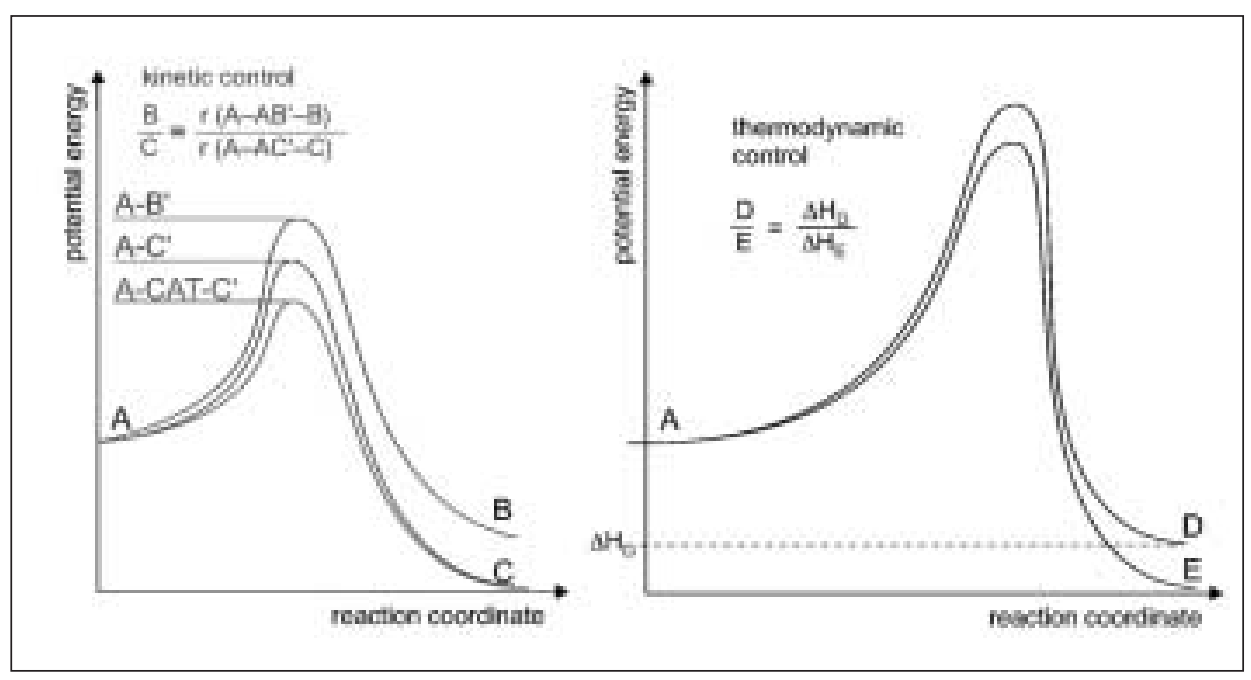

Fig. 6. Potential energy profile: kinetic reaction vs. thermodynamic reaction, catalysis.

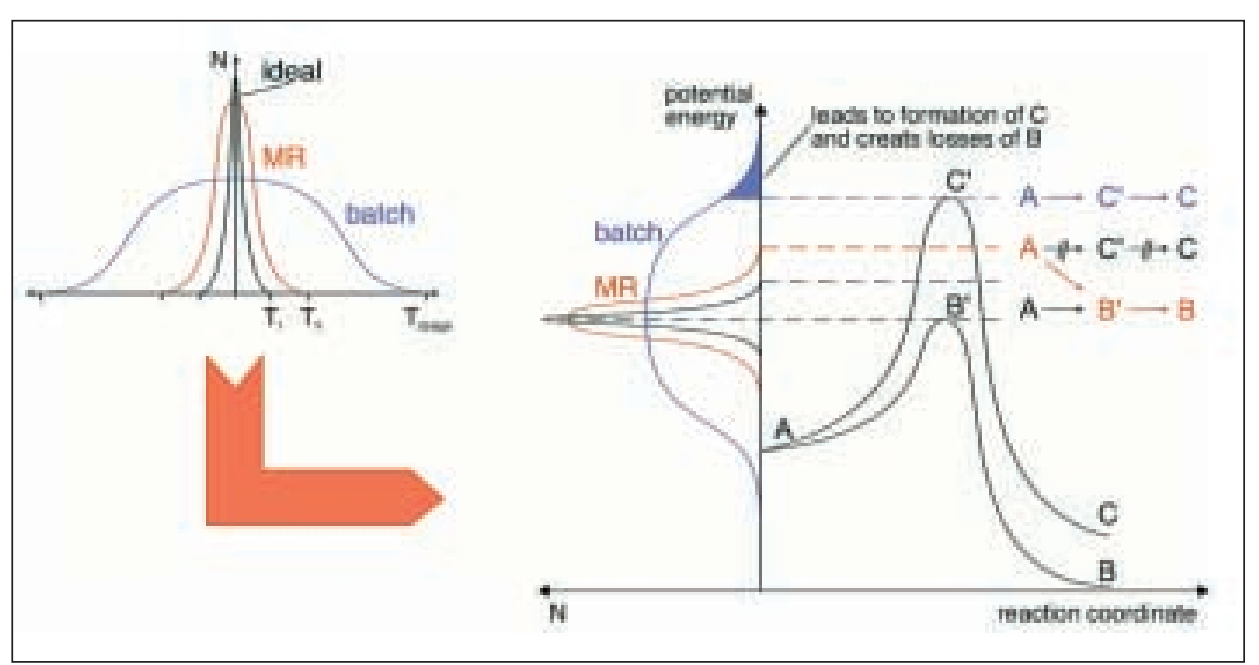

Fig. 7. Temperature and activation energy, temperature quality and activation energy.

Whilst catalysis research has been a field of extensive activity for quite some time and has led to the formation of highly successful new companies and revitalized existing players, microreaction technology has only recently crossed the chasm towards infrastructural investment. Given the broader applicability and similarly sized technological impact and the managerial expectations from the use of the technology we are prepared to catch up quickly.

\subsubsection{Replication and Adaptation to Procure and Modify Quantity}

Natural organisms operate principles for the production of functional molecules that can serve as guiding principles in the search for optimized industrial chemical synthesis. To increase production output production rates of molecules in cells are increased and additional production units/ cells are utilized or even made. Nature integrates closed loop quality and quantity control back up to the organism level through cascades of control loops. It organizes mass and information flow in a steady manner with transient specific events. The point is, nature does so with sufficient process robustness and operating reliability.

Chemical synthesis in microreactors today successfully copies many of these mechanisms. Most importantly microreactors can be operated for a short time span to produce small amounts of functional molecules required in early functional testing phases. As continuously operated process plants they can procure significantly higher quantities by simply increasing the number of consecutive operating hours. Parallel arrays of reactors then serve to massively manufacture functional chemicals. Also, production rates within microreactors can 
be successfully increased. Fast learning protocols can incorporate real-time feedback loops of control. Mass flow in a microreactor synthesis scheme is steadily organized and transient synthetic events are being managed.

However, there still is a sufficiently wide gap to the vision of self-controlled learning and production systems [17]. Therefore managing an appropriate process organization is important to realize the benefits of the technology.

\subsection{Knowledge Management and the Human Factor in Chemical Synthesis}

The chemical synthesis knowledge of a molecular function stems from selecting desired molecule structures from the configurational space of conceivable structures, a selection of chemical methods to build these structures from the chemical diversity space that is comprised amongst others by structural construction strategy, synthesis sequence, choice of reactions and reagents as well as a selection of reaction conditions from the physico-chemical diversity space.

Classical chemistry process organizations are structured as depicted in Fig. 8. Discovery delivers unifocal points, hits from the configurational space of conceivable molecular structures to fulfill a function, functional chemistry (in pharmaceutical firms called medicinal chemistry) measures the configurational space surrounding initial hits and therefore develops initial synthesis strategy and sequence. Chemical development selects from within the chemical diversity space often thereby developing new synthesis strategies and sequences in a response aimed at catering timely with sufficient quantities of testing materials to the needs of remote qualification procedures. Process development finally determines the physico-chemical parameter set required to safely and reliably conduct chemical production. Process robustness concerns further fuelled with material cost concerns where a fine chemicals production perspective rules the effort lead to review chemistry choices that can range as far as to redefine synthetic sequence. Thus classical chemistry process organizations tend to strive for cost leadership positioning of chemical synthesis, a questionable priority where time to market rewards industry leaders with sustained growth and above industry average profitability.

Chemical synthesis in microreactors through cellular process chemistry allows a new vision of chemical process organizations wherein the scarce factor of proficient scientific resources is bundled in an organ- ization that delivers the choices within knowledge space based on experimental learning cycles in the laboratory and an organization that provides production infrastructure within a framework resembling automotive assembly (Fig. 9).

The managerial aspects of chemical synthesis are not a subject of this paper [18], however the organizational format for chemical synthesis today impacts on technological choices. These in turn frame a retrograde view on performance criteria of novel synthesis technology and should therefore briefly be hinted at. Discrete high volume production runs are determining

peak storage volumes and legal complexity of dealing with many highly reactive chemicals. Handling challenges associated with these materials in manual transmission to batch vessels, potential emission hazards and run-away exotherms from batch vessel hold-ups are not a problem for chemical synthesis in microreactors (for direct fluorination see [8]). Plant security is an important feature in chemical production facilities. Exothermal deprotonations in batch processes are often moderated by slow dissolution of solid bases (e.g. carbonate) in organic solvents. In contrast to this highly reactive bases (such as BuLi) are suitable

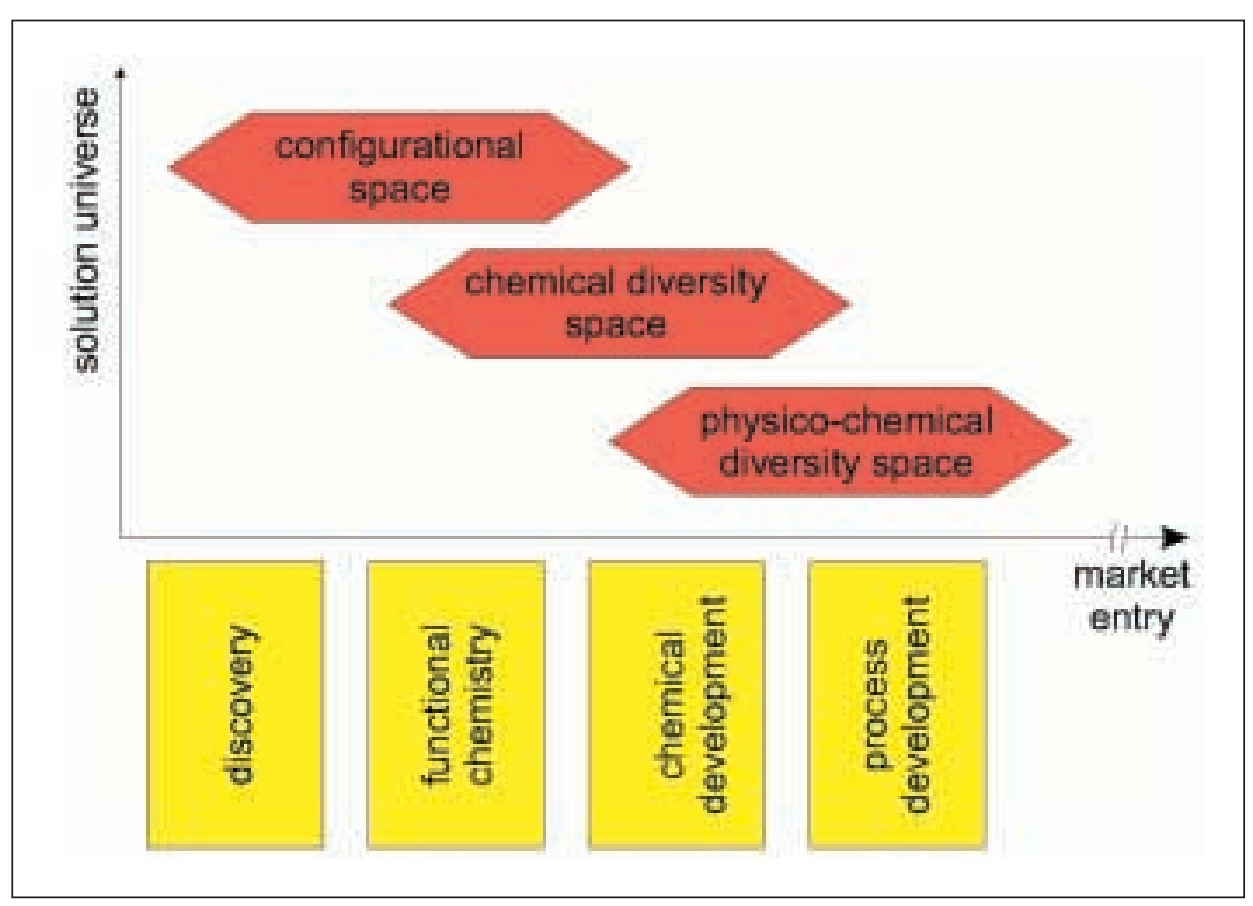

Fig. 8. Classical chemistry process organizations.

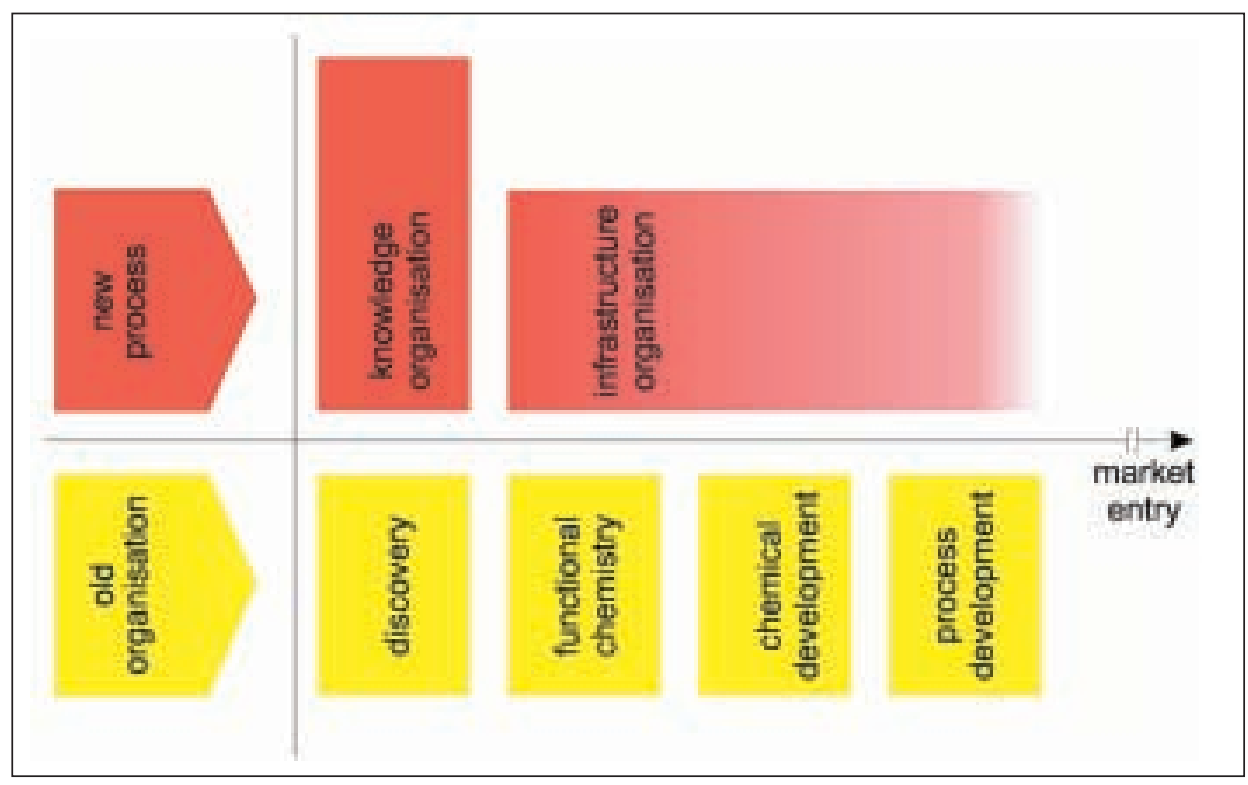

Fig. 9. Current trends in organizing chemistry R\&D. 
for direct application in microreactors because of their improved temperature control.

Another example is the preference for reactions releasing gaseous by-products as a means of ensuring irreversible reaction conduct of exergonic reactions over more exothermal reaction conduct. Many of these choices are questionable in the regime of chemical synthesis in microreactors.

\section{Retrograde Perspective on Chemical Synthesis in Microreactors}

From a retrograde perspective three perceptive obstacles retarded the early adaptation of microreactors in chemical synthesis in continental Europe. Assuming that Stokes radii, and hence their diffusion coefficients, differ from molecule to molecule as reaction rates do from reaction to reaction wouldn't every reaction require a tailor-made reactor? Wouldn't the applicability of microreactors be severely limited by clogging from the formation of solid products or by-products and excessive reaction times? And even if broad synthetic applicability were established wouldn't the technology fail in transfer to production? Shouldn't it at least be hopelessly expensive?

\subsection{Broad Applicability}

Very few reactions of near diffusion controlled kinetics are successfully deployed in industrial functional molecule synthesis. As discussed above microreactors exhibit tremendously improved control of diffusion over batch vessels and it should suffice to indicate that reaction times i.e. residence times can be adjusted within approximately two orders of magnitude by varying flows. In conclusion widely standardized reactors are conceptually valid.

In a recent paper Haswell et al. [19] summarized the broad applicability of microreactors to organic reactions. At a conference [5a], scientists from a pharmaceutical firm presented a wide range of organic chemical reactions conducted in microreactors; the paper was however not published in the conference proceedings. Further to these findings several process patents [20] were filed later. Our own research was aimed at showing how chemical reactions examined in the context of a broadly accepted grid could be transferred to microreactors. We chose the classification from a standard text book [21] of chemical reactions and demonstrated reactions within all classes of transformations (Table 2). Further to these systematic efforts at screening the applicability of
Table 2. Examples for application of MRT for standard reactions.

Entry Reaction Type and example

Radical substitution

1

Nucleophilic substitution on sat. hydrocarbons

2

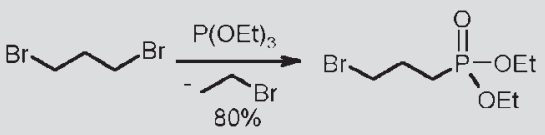

Elimination to generate $\mathrm{C}-\mathrm{C}$ double bonds

3

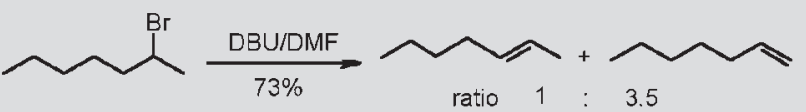

Addition to non-activated C-C multiple bonds
$4 a$

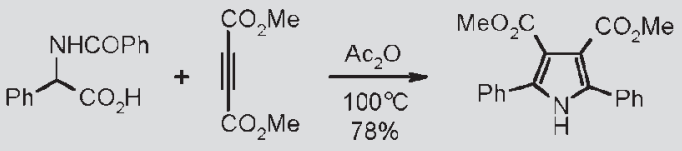

$4 b$

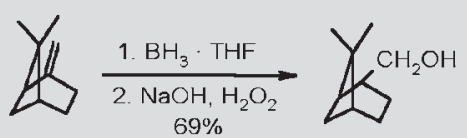

Electrophilic and nucleophilic substitution to aromatic systems

$5 a$

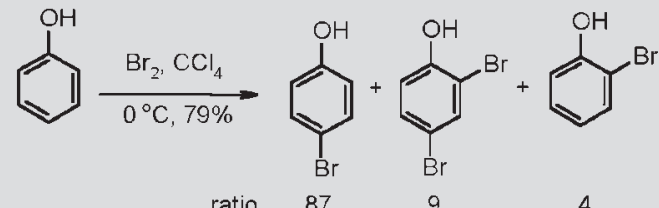

$5 b$

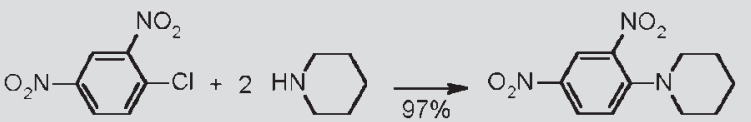

Oxidation and Reduction

$6 a$

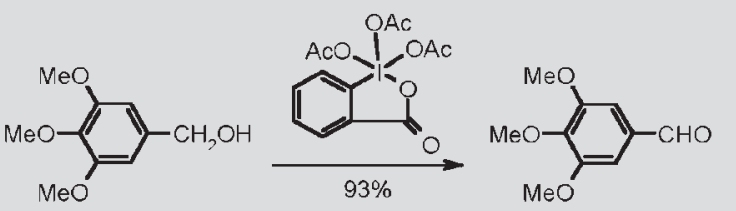

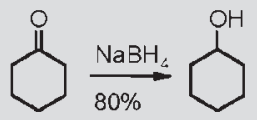

Reactions of carbonyl compounds

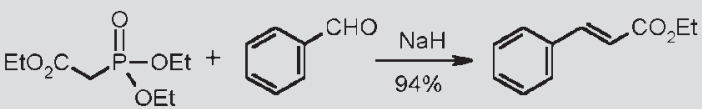

Rearrangements

8

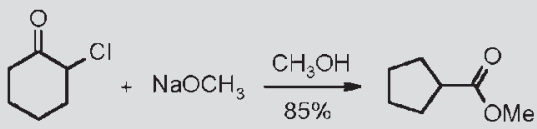


microreactors in chemical synthesis many more findings examined the improvement of conversion, yields and selectivity of reactions and are discussed below.

\subsection{Production Capability and Cost Comparison}

The suitability of microreactors for production purposes was a priori questioned on three dimensions. It was believed that particle formation during reactions should lead to clogging of microreactors. The scalability of throughput to meaningful quantities was doubted. So was, finally in the absence of concepts on a basic engineering level, their comparative economics.

In a recent paper [26] it was shown that diazo pigment chemistry could be advantageously conducted in microreactors (Scheme 1). In a three step sequence wherein each step either starts with suspensions of crystalline starting materials in a solvent or leads to the formation of crystalline products a more narrow crystal size distribution was accomplished and improved overall pigment quality achieved. So far, the process was implemented to the pilot production scale providing an output of 10 tpa using MR equipment as shown in Fig. 10. Further regarding the formation of solids in microreactors, Wittig olefinations and Mitsunobu esterifications were performed successfully on the laboratory scale in MR systems without any problems with precipitated $\mathrm{OPPh}_{3}$ (Table 4 in chapter 5, entry 8).

In another case a Grignard reaction has been taken to the pilot plant scale $[5 a, b]$ and the manufacture of a vitamin precursor in microreactors has been cited [5c,d].

Economic comparisons of conventional technologies with microreactors have been discussed. Although we reserve specific comparisons to the consultative assignments of our engineering practice, Table 3 gives an exemplary comparison for an investment decision into a chemical development pilot unit. In this calculation a microreactor array is invested in place of a 501 batch vessel in a pilot plant environment. Each new product introduced to this batch environment goes through a scale up effort of 10 man days. The resources required to operate the batch environment are doubled. When running the same process in a microreactor array the scaling effort is saved and fewer personnel are required to operate the continuous process. In this cost comparison calculation it is assumed that yields are increased moderately and further the solvent consumption is reduced marginally from lower thermal buffering requirements. Whilst total installed cost of a microreactor unit in this environment ex-

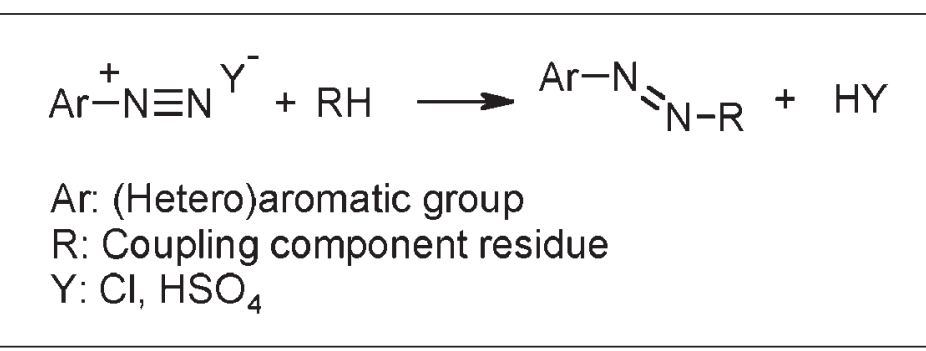

Scheme 1. General scheme for diazo pigment synthesis.

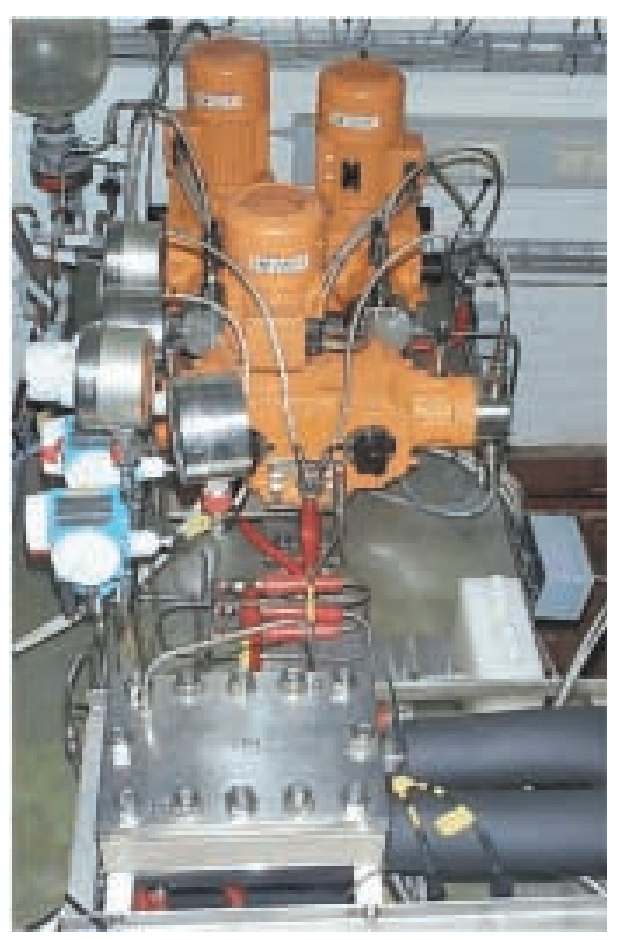

Fig. 10. MR pilot production plant developed and built by CPC - Cellular Process Chemistry Systems $\mathrm{GmbH}$.

Table 3. Comparison of cost for production in a batch vessel and in the microreactor.

\begin{tabular}{lcc}
\hline & 50 litre batch vessel & MR array \\
\hline Investment & $96.632 €$ & $430.782 €$ \\
Scale-up effort & 10 man days & 0 man days \\
Mean yield & $90 \%$ & $93 \%$ \\
Specific solvent consumption & $10.0 \mathrm{l} / \mathrm{kg}$ & $8.3 \mathrm{l} / \mathrm{kg}$ \\
Required personnel per facility & $2 \mathrm{men}$ & $1 \mathrm{man}$ \\
Production rate & $427 \mathrm{~kg} / \mathrm{a}$ & $536 \mathrm{~kg} / \mathrm{a}$ \\
Specific production cost & $7.227 € / \mathrm{a}$ & $2917 € / \mathrm{a}$ \\
Cost advantage of MR array & & $2.308 .529 € / \mathrm{a}$ \\
Return on investment & & $0.14 \mathrm{a}$ \\
\hline
\end{tabular}


Table 4. Examples for efficiently running reactions in MRT. Throughput rates in $(\mathrm{g} / \mathrm{h})$ are in brackets attached to the yields.

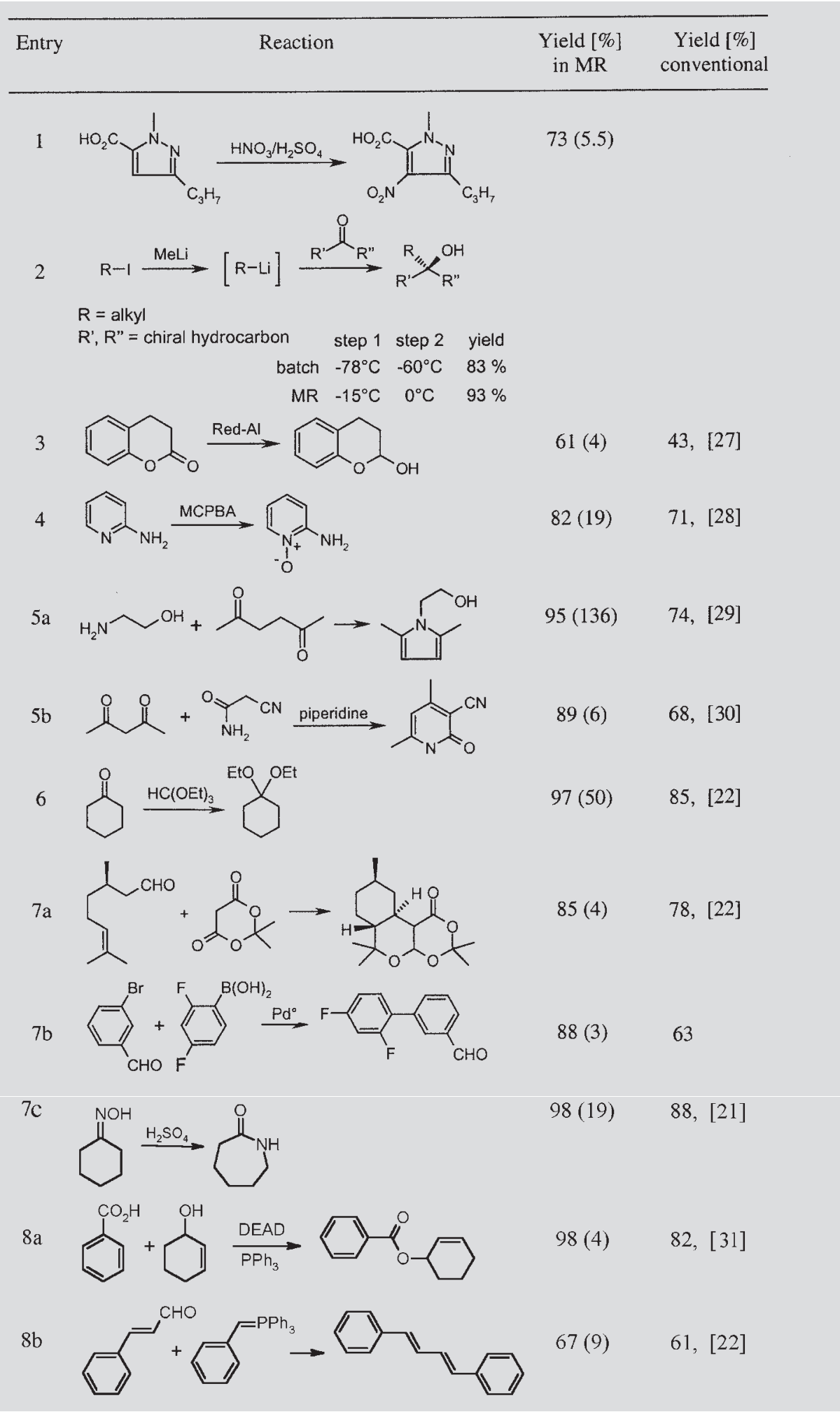

ceeds the cost of a conventional unit, the internal rate of return fuelled by operating cost savings boils down to a fraction of a year.

\section{Step 1: Better Chemistry}

Beyond a removal of the generalized doubt of applicability that confronted the technology, its potential for a better chemistry was and remains a worthwhile field of examination. Important examples (Table 4) of improved reactions so far are nitrations (entry 1), lithiations leading to metallorganic intermediates and the reaction of these metallorganic intermediates in general with electrophiles (2). Other examples are reduction (3) and oxidation reactions (4), several highly exothermal cyclocondensations (5) as well as even some tricky, entropically driven transacetalisations (6) and special applications (7 and 8).

The manufacturing scale nitration of Viagra $^{\mathrm{TM}}$ intermediate (Table 4, entry 1 ) for instance required several years of chemical development. Running the nitration under conventional conditions initially resulted in a significant amount of losses to side-reactions, such as e.g. the decarboxylated product as a result of lacking temperature control. Such sensitive chemistry is an obvious candidate for synthesis in microreactors. In our hands, laboratory yields of the Viagra $^{\mathrm{TM}}$ intermediate were immediately achieved in a microreactor and maintained throughout the production run. This reaction protocol demonstrates how chemical R\&D processes can be significantly accelerated.

In another example 3 the lithiation of starting material yields an unstable intermediate that is prone to beta-elimination. A lithiation at the laboratory scale was possible under cryogenic conditions. The subsequent addition to a ketone was furbished at $-60{ }^{\circ} \mathrm{C}$ to yield an overall $83 \%$ of the alcohol. In a microreactor not only could the lithiation be conducted at $-15{ }^{\circ} \mathrm{C}$ and the addition at $0{ }^{\circ} \mathrm{C}$, a change towards significantly lower investment and operating cost when performed in production, but the yield could also be increased to $93 \%$. Conventionally it was not possible to scale the process. Again, the example shows how the tighter reaction control in MR enables new synthesis of functional molecules in straightforward goal orientation.

\section{Step 2: Better Chemical Synthesis}

Ultimately chemical synthesis in microreactors is performed more rapidly and 
more reliably to provide more flexible quantities of better quality functional molecules in higher yields at improved economics. In one published example [32] a multistep synthesis of ciprofloxacin ${ }^{\mathrm{TM}}$ in microreactors (Scheme 2) was conducted. In several bilateral industrial projects synthesis sequences for functional molecules are developed in microreactors.

In one example information on the existence of such a project has been released. An already marketed blockbuster synthesis is transferred to a microreactor with an intention of transferring the continuous process to production in microreactors.

\section{Step 3: Cellular Process Chemistry Systems}

From a system performance perspective the hitherto discussed improved synthesis of functional molecules on the laboratory as well as on the production scale required an integration with the mechanisms to select targets within the space of configuration, chemical and physico-chemical diversity (for polymer supported microreactions see [33]).

More recently a new concept for combinatorial experimentation has been completed (Fig. 11). Whilst it aims at the synthesis of focused compound libraries and at selecting the right reagent choices to conduct synthesis it organizes around the same scaleable process used throughout the chemical synthesis process. Within this concept variations on starting materials $\mathrm{A}$ and $B_{x}$ are sequentially reacted in a microreactor process plant to yield a variety of $\mathrm{C}_{\mathrm{x}}$. In one example sequence the technology has been used to synthesize a variety of amides from amines and acid anhydrides (see Scheme 3, results are given in Table 5). It is currently also being used to optimize reactions through the variations of auxiliaries and solvents and might become an interesting and more direct alternative to solid phase synthesis.

Also coupling to in-line analytics has resulted in a new high-throughput tool for the optimization of continuous reactions. The transient nature of experiments in these set-ups allows for a rapid adaptation of syn-

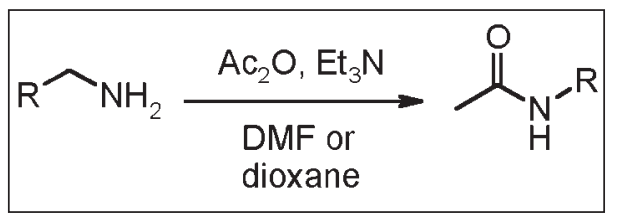

Scheme 3. Acylation of amines as a demonstration experiment in MR.

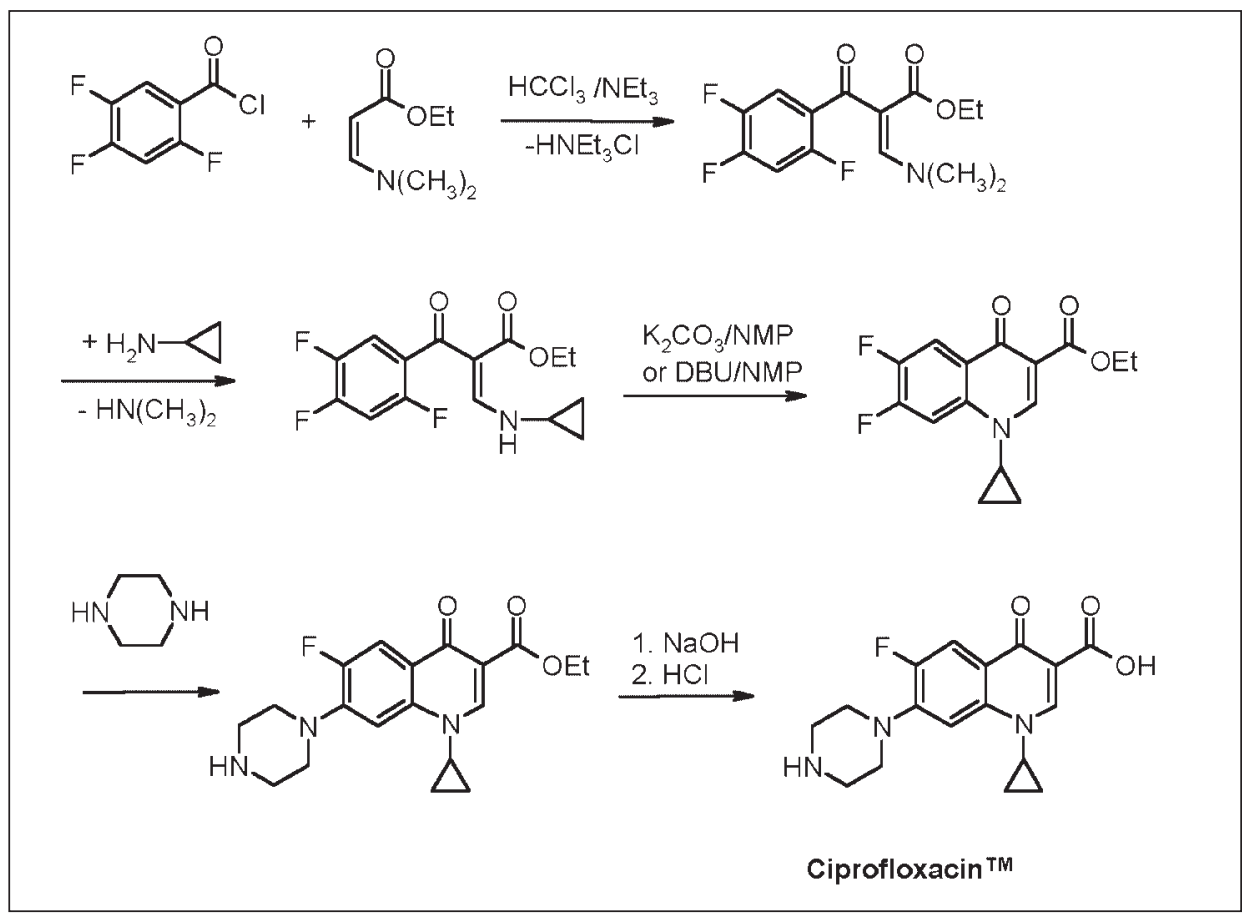

Scheme 2. Synthesis of ciprofloxacin ${ }^{\mathrm{TM}}$ performed in a MR.

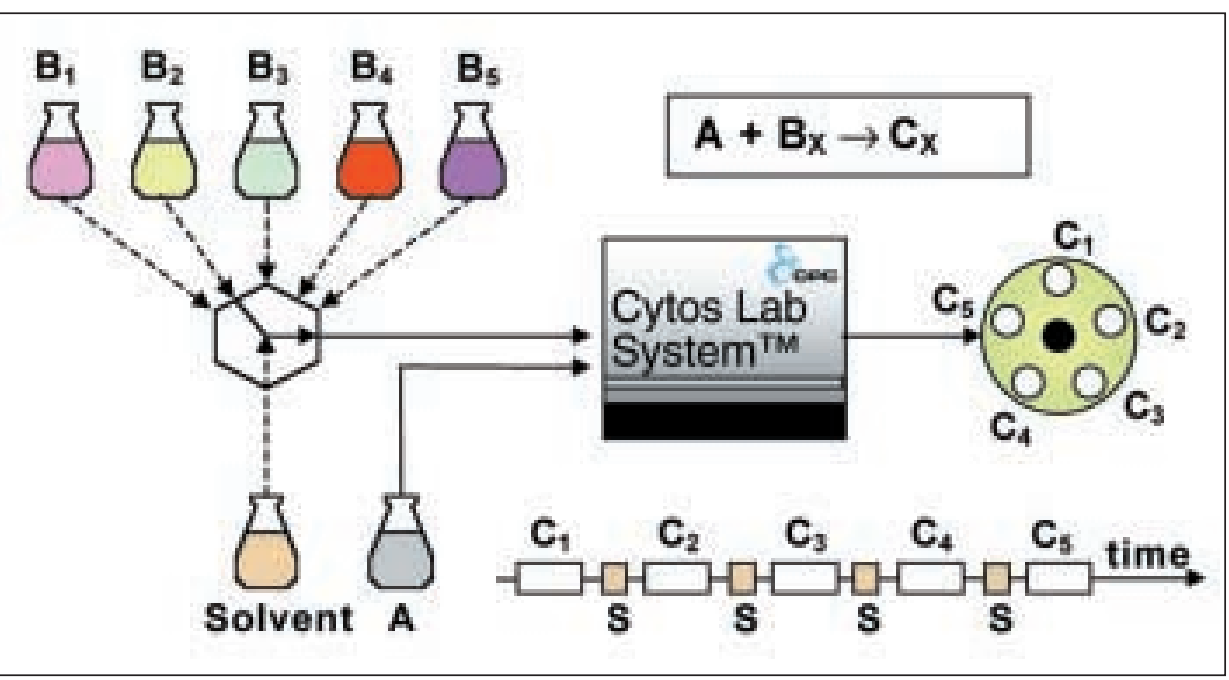

Fig. 11. General scheme for combinatorial experiments in MR.

thesis towards its optimal conditions, which we have shown to scale at negligible effort. Although this new regimen developed in our group lends itself amongst others particularly to temperature sensitive reactions, moisture sensitive reactions, kinetically controlled $\mathrm{C}-\mathrm{C}$ bond formation processes and homogenous catalysis in the field of synthesis of targeted i.e. hypothesis driven libraries, it is of similar importance to the optimization of solvent and reagent choices from the chemical diversity space as well as to the procurement of testing samples. These can be made in all practical quanti- ties required by functional screening methods and obviously manufactured under the same conditions when desired.

In the example given in Fig. 12 the impact of a steady change in temperature on conversion is monitored in-line real time. Similar experiments have been conducted with changes in residence times and concentration. Both these adaptations of microreaction technology are pivotal elements of the artificial optimization of reactions within cellular process chemistry knowledge systems. 
Table 5. Results for the acylation of several amines.

\begin{tabular}{clccc}
\hline Entry & Amine & Residence Time [min] & Yield [\%] & Throughput [g/h] \\
\hline 1 & 1-propylamine & 13 & 98 & 6.4 \\
2 & 1-butylamine & 13 & 99 & 7.4 \\
3 & 1-pentylamine & 2 & 99 & 49.8 \\
4 & 1-hexylamine & 4 & 100 & 27.8 \\
5 & 1-heptylamine & 1 & 94 & 6.7 \\
6 & 1-octylamine & 4 & 99 & 32.9 \\
7 & 1-nonylamine & 2 & 95 & 68.3 \\
8 & 3-methyl-2-butylamine & 1 & 85 & 5.0 \\
9 & 2-methyl-2-butylamine & 1 & 75 & 4.4 \\
10 & t-butylamine & 13 & 70 & 5.2 \\
11 & cyclopentylamine & 2 & 100 & 49.5 \\
12 & cyclohexylamine & 13 & 89 & 8.2 \\
13 & cycloheptylamine & 2 & 83 & 50.3 \\
14 & aniline & 1 & 99 & 6.1 \\
15 & 1-naphthylamine & 1 & 46 & 3.8 \\
\hline
\end{tabular}

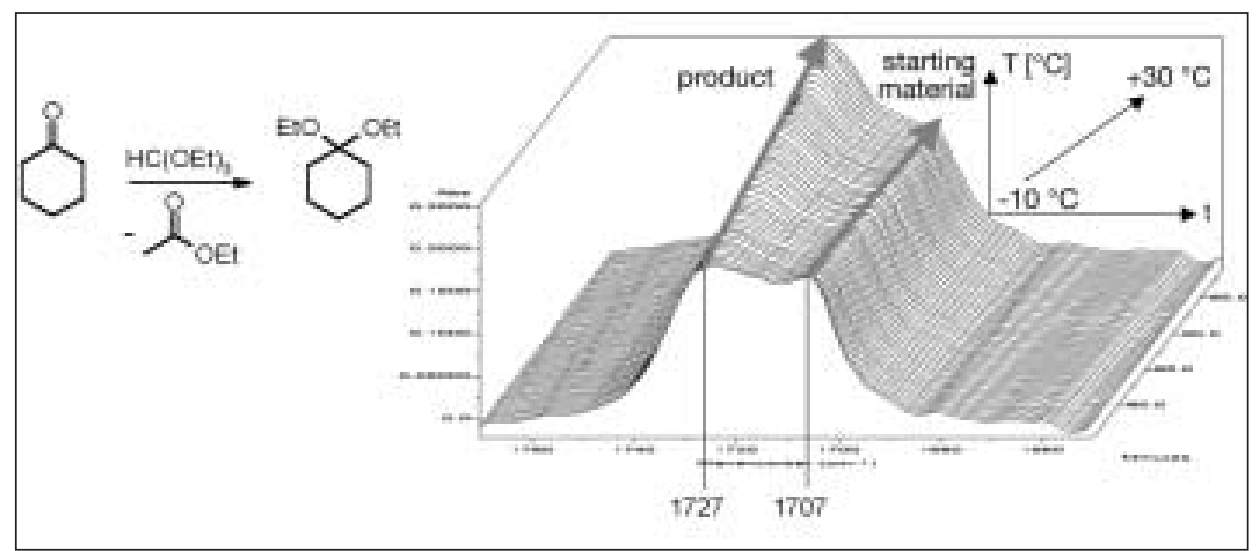

Fig. 12. Ketalization reaction of cyclohexanone. The reaction can be monitored by following the starting material to product (for detection purposes the ethyl acetate is recorded) ratio in IR spectra (wavenumbers are given in $\mathrm{cm}^{-1}$, right).

\section{Conclusion and Outlook}

Chemical synthesis in microreactors has demonstrated broad applicability to the wide universe of chemical reactions. In many cases better yields and higher selectivities are predictably accomplished. Current research within the author's team and elsewhere aims at unraveling and exploiting steeper energy gradient synthesis regimes to ultimately evolve with shorter and more economical chemical research, development and manufacturing of functional molecules. As the technology was proven fit for production and technologies for the learning of chemistries have been aggregated, we now expect to see its rapid application in the synthesis of new chemical entities in high value added market segments.

\section{Acknowledgement}

The authors would like to thank their colleagues and coworkers at CPC - Cellular Process Chemistry Systems for their contribution to the results summarized in this article. We are most grateful for the following research grants: The Ministry of Economics of the State of Rhineland Pallatinate supported the work on combinatorial experimentation. Another part of the ongoing research that is partially reported herein is funded by the Deutsche Bundesstiftung Umwelt.
[1] T.M. Floyd, M.W. Kopp, S.L. Firebaugh, K.F. Jensen, M.A. Schmidt, 'Novel liquid phase microreactors for safe production of hazardous specialty chemicals', in $\mathrm{Mi}$ croreaction Technology: 3rd International Conference on Microreaction Technology, Proceedings of IMRET 3, Ed. W. Ehrfeld, Springer, Berlin, Germany, 2000, p. 171.

[2] a) V. Hessel, W. Ehrfeld, K. Golbig, C. Hofmann, S. Jungwirth, H. Löwe, T. Richter, M. Storz, A. Wolf, O. Wörz, J. Breysse, 'High temperature HCN generation in an integrated Microreactor system', in Microreaction Technology: 3rd International Conference on Microreaction Technology, Proceedings of IMRET 3 , Ed. W. Ehrfeld, Springer, Berlin, Germany, 2000, p. 151; b) A. Kursawe, D. Hönicke, 'Epoxidation of ethene with pure oxygen as a model reaction for evaluating the performance of microchannel reactors', in Proceedings of the 4th International Conference on Microreaction Technology, IMRET 4, March 5-9 2000, Atlanta, USA, p. 153; c) H. Kestenbaum, A. Lange deOlivera, W. Schmidt, H. Schüth, W. Ehrfeld, K. Gebauer, H. Löwe, 'Synthesis of ethylene oxide in a catalytic microreactor system', in Proceedings of the 12th Int. Conference on Catalysis, 2000, Grenada, Spain; d) R. Maurer, C. Claivaz, M. Fichtner, K. Schubert, A. Renken, 'A microstructured reactor system for the methanol dehydrogenation to water-free formaldehyde', in Proceedings of the 4th International Conference on Microreaction Technology, IMRET 4, March 5-9, 2000, Atlanta, USA, p. 100; e) J. Mayer, M. Fichtner, D. Wolf, K. Schubert, 'A microstructured reactor for the catalytic partial oxidation of methane to syngas', in Microreaction Technology: 3rd International Conference on Microreaction Technology, Proceedings of IMRET $3, \mathrm{Ed} . \mathrm{W}$. Ehrfeld, Springer, Berlin, Germany, 2000, p. 187; f) A.L.Y. Tonkovich, J.L. Zilka, M.R. Powell, C.J. Call, 'The catalytic partial oxidation of methane in a microchannel chemical reactor', in: Process Miniaturization: 2nd International Conference Preprints, Eds. W. Ehrfeld, I.H. Rinard, R.S. Wegeng, AIChE, New Orleans, USA, 1998, p. 45.

[3] a) E. Ditzsche, D. Hönicke, M. Fichtner, K. Schubert, G. Weißmeier, 'The formation of cycloalkenes in the partial gas phase hydrogenated of C,T,T-1,5,9-cyclodecatriene, 1,5-cyclooctadiene and benzene in microchannel reactors', in Pro- 
ceedings of the 4th International Conference on Microreaction Technology, IMRET 4, March 5-9, 2000, Atlanta, USA, p. 89; b) S. Walter, E. Joannet, M. Schiel, I. Boullet, R. Phillips, M.A. Liauw, 'Microchannel reactor for the partial oxidation of isoprene', in Proceedings of the 5th International Conference on Microreaction Technology, IMRET 5, May 27-30, 2001, Strasbourg, France; c) S. Kah, D. Hönicke, 'Selective oxidation of 1-butene to maleic anhydride - comparison of the performance between microchannel reactors and fixed bed reactors', in Proceedings of the 5th International Conference on Microreaction Technology, IMRET 5 , May 27-30, 2001, Strasbourg, France, p. 397; d) A. Zheng, F. Jones, J. Fang, T. Cui, 'Dehydrogenation of cyclohexane to benzene in a membrane reactor', in Proceedings of the 4th International Conference on Microreaction Technology, IMRET 4, March 5-9, 2000, Atlanta, USA, p. 400.

[4] J. Schiewe, W. Ehrfeld, V. Haverkamp, V. Hessel, H. Löwe, C. Wille, M. Altvater, R. Rietz, R. Neubert, 'Micromixer based formation of emulsions for pharmaceutical applications', in Proceedings of the 4th International Conference on Microreaction Technology, IMRET 4, March 5-9, 2000, Atlanta, USA, p. 467.

[5] a) H. Krummradt, U. Kopp, J. Stoldt, 'Experiences with the use of microreactors in organic synthesis', in Microreaction Technology: 3rd International Conference on Microreaction Technology, Proceedings of IMRET 3, Ed. W. Ehrfeld, Springer, Berlin, Germany, Germany, 2000, p. 181; b) A. Förster, Chemie Ingenieur Technik plus 2001, 4, 28; c) V. Hessel, H. Löwe, Chemie Ingenieur Technik 2002, 74, 186; d) O. Wörz, K.P. Jäckel, K.P. Richter, A. Wolf, Chem. Eng. Technol. 2001, 24, 138.

[6] V. Skelton, G.M. Greenway, S.J. Haswell, P. Styring, D.O. Morgan, S. Wong, 'Micro reaction technology: synthetic chemical optimization methodology of Wittig synthesis enabling semi-automated micro reactor for combinatorial screening', in Proceedings of the 4th International Conference on Microreaction Technology, IMRET 4, March 5-9, 2000, Atlanta, USA, p. 78.

[7] V. Skelton, G.M. Greenway, S.J. Haswell, 'Microreactor synthesis: synthesis of cyanobiphenyls using a modified Suzuki coupling of an aryl halide and aryl boric acid', in Microreaction Technology: 3rd International Conference on Microreaction Technology, Proceedings of IMRET 3 , Ed. W. Ehrfeld, Springer, Berlin, Germany, 2000, p. 235.

[8] N. De Mas, R.J. Jackman, M.A. Schmidt, K.F. Jensen, 'Microchemical Systems for direct fluorination of aromatics', in Proceedings of the 5th International Conference on Microreaction Technology, IMRET 5, May 27-30, 2001, Strasbourg, France, p. 60.

[9] H. Lu, M.A. Schmidt, K.F. Jensen, Lab on a Chip 2001, 1, 22.

[10] J. Antes, T. Tuerecke, E. Marioth, K. Schmid, H. Krause, S. Loebbecke, 'Use of microreactors for nitration processes', in Proceedings of the 4th International Conference on Microreaction Technology, IMRET 4, March 5-9, 2000, Atlanta, USA, p. 194.

[11] a) R.B. Woodward, Pure Appl.Chem. 1973, 33, 145; b) A. Eschenmoser, XXIII International Congress Pure and Applied Chemistry, Boston, Butterworths London, 1971, 2, 69.

[12] R. Armstrong, J.-M. Beau, S.H. Cheon, W.J. Christ, H. Fujioka, W.-H. Ham, L.D. Hawkins, H. Jin, S.H. Kang, Y. Kishi, M.J. Martinelli, W.W. McWhorter, M. Mizuno, M. Nakata, A.E. Stutz, F.X. Talamas, M. Taniguchi, J.A. Tino, K. Ueda, J.-I. Uenishi, J.B. White, M. Yonaga, J. Am. Chem. Soc. 1989, 111, 7525 .

[13] A. Kleemann, J. Engel, B. Kutscher, D. Reichert, 'Pharmaceutical Substances', 3rd ed., Thieme, Stuttgart, New York, 1999.

[14] a) E.J. Corey, Angew. Chem. Int. Ed. Engl. 1991, 30, 455; b) D. Seebach, Angew. Chem. Int. Ed. Engl. 1990, 29, 1320.

[15] B.M. Trost, Angew. Chem. Int. Ed. Engl. 1995, 34, 259.

[16] R.T. Morrison, R.N. Boyd, 'Organic Chemistry', 4th ed., Allyn and Bacon, Boston, USA, 1983.

[17] In a recent paper Haswell and coworkers envisioned a fluidic system that would embrace synthesis and biological testing of functional molecules: a) P. Watts, C. Wiles, S.J. Haswell, E. Pombo-Villar, Tetrahedron 2002, 58, 5427; b) P.D.I. Fletcher, S.J. Haswell, E. Pombo-Villar, B.H. Warrington, P. Watts, S.Y.F. Wong, X. Zhang, Tetrahedron 2002, 58, 4735.

[18] T. Schwalbe, K. Sahin, Scaling in chemical R\&D: TOC in search of a stable constraint, to be published.

[19] S.J. Haswell, R.J. Middleton, B. O'Sullivan. V. Skelton. P. Watts, P. Styring, Chem. Comm. 2001, 391.

[20] a) Wurziger (Merck Patent GmbH) WO 01 09091, 1999; b) Wurziger (Merck Patent GmbH) WO 01 70387, 2000; c) Wurziger (Merck Patent GmbH) WO 0183466 , 2000; d) Wurziger (Merck Patent GmbH) WO $0192225,2000$.

[21] H.G.O. Becker, G. Domschke, E. Fanghängel, M. Fischer, K. Gewald, R. Mayer, D. Pavel, H. Schmidt, K. Schwetlick, W. Berger, J. Faust, F. Gentz, R. Gluch, K. Müller, K. Schollberg, E. Seiler, G. Zeppenfeld, 'Organikum', Verlag der Wissenschaften, Berlin, Germany, 1990.

[22] L.F. Tietze, T. Eicher, 'Reactions and synthesis in the organic chemistry laboratory', University Science Books, Herndon, USA, 1986.

[23] D. Spiegel, M. Utermann, Chem. Ber. 1906, 2632.

[24] D.B. Dess, J.C. Martin, J. Org. Chem. 1983, 48, 4155.

[25] D.W. Goheen, W.R. Vaughan, Org. Synth.Coll. Vol. IV, 594.

[26] C. Wille, V. Autze, H. Kim, U. Nickel, S. Oberbeck, Th. Schwalbe, L. Uverdorben, 'Progress in transferring Microreactors from lab into production - an example in the field of pigment technology', in Proceedings of the 6th International Confer- ence on Microreaction Technology, IMRET 6, March 10-14, 2002, New Orleans, USA, p. 7.

[27] R. Kanazawa, T. Tokoroyama, Synthesis 1976, 526.

[28] L.W. Deady, Synthetic Communications 1977, 509.

[29] P. Buu-Hoi Ng, J. Org. Chem. 1955, 20, 639.

[30] A.R. Katritzky, Adv. Heterocycl. Chem. 1963, $1,347$.

[31] B.K. Shull, T. Sakai, J. Org. Chem. 1987, 62, 8294.

[32] CPC - Cellular Process Chemistry Systems GmbH, EP 0116024-A2, 2001.

[33] S.V. Ley, I.R. Braxendale, Nature Reviews 2002, 1, 573. 